\title{
Creativity and mental disorder: family study of 300000 people with severe mental disorder ${ }^{\dagger}$
}

\author{
Simon Kyaga, Paul Lichtenstein, Marcus Boman, Christina Hultman, Niklas Långström
} and Mikael Landén

\section{Background}

There is a long-standing belief that creativity is coupled with psychopathology.

\section{Aims}

To test this alleged association and to investigate whether any such association is the result of environmental or genetic factors.

\section{Method}

We performed a nested case-control study based on swedish registries. The likelihood of holding a creative occupation in individuals who had received in-patient treatment for schizophrenia, bipolar disorder or unipolar depression between 1973 and 2003 and their relatives without such a diagnosis was compared with that of controls.

\section{Results}

Individuals with bipolar disorder and healthy siblings of people with schizophrenia or bipolar disorder were overrepresented in creative professions. People with schizophrenia had no increased rate of overall creative professions compared with controls, but an increased rate in the subgroup of artistic occupations. Neither individuals with unipolar depression nor their siblings differed from controls regarding creative professions.

\section{Conclusions}

A familial cosegregation of both schizophrenia and bipolar disorder with creativity is suggested.

\section{Declaration of interest}

None.
Creativity has long been associated with mental disorder, epitomised by Aristotle's claim that 'no great genius has ever existed without a strain of madness.' ${ }^{1}$ Today, it is still a common view that prominent creative individuals frequently have a psychiatric disorder and that creativity is enhanced in specific mental disorders. ${ }^{2}$ One reason to study the alleged link between creativity and psychopathology is to gain a deeper understanding of patients' needs and experiences. Creativity is a source of wellbeing and loss of creativity is experienced as unpleasant. ${ }^{3}$ People with schizophrenia and bipolar disorder ${ }^{4}$ often discontinue medication because of reported loss of creativity and other cognitive impairments. A link between creativity and psychopathology is also of interest given that severe mental disorders have persisted throughout evolution despite occurring during the reproductive years. ${ }^{5-9}$

The study of the association between creativity and psychiatric disorders has primarily been addressed in two types of studies. Some studies assess psychiatric disorders in eminent, creative individuals using structured diagnostic interviews or retrospective analysis of written biographies. ${ }^{2,10-14}$ One of the earliest attempts to use this approach was Lange-Eichbaum's study of over 800 people regarded as geniuses published in $1931 .{ }^{10} \mathrm{He}$ argues that it is within the group of individuals with exceptional gifts and a concomitant psychopathology that history's greatest geniuses are found; exemplified by Michelangelo, Luther, Napoleon, Beethoven, Schopenhauer and Strindberg, among others. He states 'it cannot simply be a chance matter that among geniuses the healthy constitute only a small minority'. Following Lange-Eichbaum, Juda investigated 294 highly gifted artists and scientists born in German-speaking countries between $1650-1900 .{ }^{11}$ She concluded that there is no definite relationship between highest mental capacity and psychic illness, but that highly gifted individuals had increased rates of psychopathology. More recent studies have further strengthened these conclusions. Andreasen, for example,

†See editorial, pp. 351-352, this issue. demonstrated increased risk for affective disorder in general and for bipolar disorder in particular in 30 creative writers at the University of Iowa Writers' Workshop, compared with healthy controls. ${ }^{12}$ Similarly, Jamison found increased risk for affective disorder in 47 British writers. ${ }^{13}$ Ludwig used reviews of biographies published in the New York Times Book Review between 1960 and 1990 as selection criteria, identifying 1005 eminent individuals. Based on their biographies, he found an overrepresentation of bipolar disorder, schizophrenia-like psychosis and depression in the creative arts group. ${ }^{14}$

A few studies have evaluated creativity in people with manifest psychopathology. Santosa et al compared individuals with bipolar disorder, unipolar disorder, healthy creative, and non-creative controls using the Barron-Welsh Art Scale. ${ }^{15}$ They found that people with bipolar disorder and healthy creative controls scored higher than those with unipolar depression and non-creative controls. Another study reported increased creativity in 40 American adults with bipolar disorder compared with healthy controls using the same instrument. ${ }^{16}$ To avoid bias caused by the debilitating effects of mental illness, some studies have included relatives of those with psychiatric disorders. For example, Karlsson investigated 486 male relatives of people with schizophrenia born in Iceland between 1851 and 1940. Compared with the general population, the relatives were more often represented in a listing of prominent people. ${ }^{17}$ There was also a significant increase in those specifically successful in creative endeavours, although the number of people included were small. By comparing different branches of a kindred, Karlsson concluded that certain branches were high in both schizophrenia and giftedness, whereas others were low in both. Based on these and other findings of increased creativity in relatives of patients, ${ }^{16,18}$ including adopted children, ${ }^{19,20}$ a genetic basis for the link between creativity and psychopathology has been suggested. ${ }^{8,12}$

However, because the prior studies relied on biographical data of eminent individuals or small cohorts of patients, ${ }^{21}$ the alleged link between creativity and mental disorder warrants further 
study. Therefore, we conducted a large population-based study of the occurrence of creative occupations among individuals with schizophrenia, bipolar disorder or unipolar depression in conjunction with their relatives compared with controls without such disorders and their relatives. We also investigated whether such an association was mediated by IQ.

\section{Method}

\section{National registers}

We performed a nested case-control study using longitudinal Swedish total population registers. The primary key for register linkage was the unique personal identification number assigned to each Swedish citizen, including immigrants upon their arrival in the country. The Hospital Discharge Register (National Board of Health and Welfare) provided discharge diagnoses for all in-patient treatment episodes for schizophrenia, bipolar disorder and unipolar depression in Sweden between 1973 and 2003. The Multi-Generation Register (Statistics Sweden) enables identification of biological relatives of an index person, including all individuals born in Sweden since 1932 and whoever registered as living in Sweden after 1960. National censuses (Statistics Sweden) based on mandatory self-report questionnaires completed by all adult citizens in 1960, 1970, 1980 and 1990 provided information on professions in the entire Swedish population. Information on IQ (men only) was collected from the Military Service Conscription Register (Swedish Defence Recruitment Agency), based on compulsory conscription for all men. This information included IQ test results for all 18- to 19-year-old men between 1969 and $2006(n=1742684)$. Data were requested from the respective agencies and, following an internal ethical audit at each agency, merged by Statistics Sweden.

The Regional Ethics Committee at the Karolinska Institutet approved the study (2005/174-31/4). Informed consent was not required since data were anonymised immediately after merging by Statistics Sweden.

\section{Disease classifications}

Diagnoses were coded according to the ICD-8, ICD-9 and ICD-10. ${ }^{22-24}$ A hierarchical approach was assigned to differentiate between schizophrenia, bipolar disorder and unipolar depression. Any individual with an event in the Hospital Discharge Register of one of the diagnoses assigned to schizophrenia (ICD-8:
295.0-295.6, 295.8, 295.9; ICD-9: 295A-295G，295W，295X; ICD-10: F20) was coded as having schizophrenia. Individuals with an event of bipolar disorder (ICD-8: 296.1, 296.3, 296.8; ICD-9: 296A, 296C, 296D, 296E, 296W; ICD-10: F30, F31), but not schizophrenia, were coded as having bipolar disorder. Finally, any individual with an event of unipolar depression (ICD-8: 296.2, 300.4; ICD-9: 300E, 311; ICD-10: F32.0-F32.2, F32.4F32.9, F33-F39), but not schizophrenia or bipolar disorder, was coded as having unipolar depression. Relatives of all those with a psychiatric diagnosis and controls were not allowed to have any event of any of the three diagnoses. Schizoaffective disorder was not investigated in the present study. No information was available on individuals treated solely in out-patient facilities.

In-patient diagnoses of schizophrenia have good to excellent validity, with $94 \%$ agreement when compared with research diagnoses, based on semi-structured interviews and medical records. ${ }^{25}$ The validity on a single depressive episode in the Danish National Psychiatric Register has demonstrated sufficient precision for clinical practice, with increasing validity correlated to increasing severity $(65-83 \%){ }^{26}$ To our knowledge, no study on the validity of unipolar depression or bipolar disorder diagnoses in the Hospital Discharge Register in Sweden has been published.

\section{Creative occupations}

Occupation from the censuses was coded according to the Nordic Classification of Occupations. ${ }^{27}$ As suggested by previous authors, artistic and scientific occupations were defined as creative professions (Table 1). ${ }^{11,28,29}$ Artistic occupations were further subdivided into visual and non-visual artistic occupations to accommodate for domain-specific differences in creativity. ${ }^{30}$ Throughout this article, creative professions denotes the aggregated artistic and scientific occupations, whereas creative occupations is used for creative professions as well as for any of the subgroups (i.e. artistic, scientific, visual artistic and non-visual artistic). Individuals reporting a creative occupation in at least one of the censuses were considered creative. Individuals without information on occupation (including those reporting no occupation or unspecified occupation) were excluded from the analyses. Finally, a less creative group (accountants and auditors) was defined to test the specificity of the creative occupations. This is in line with Holland's widely used theory of vocational personalities and work environments, which considers

\begin{tabular}{|c|c|c|c|c|c|c|c|}
\hline \multirow[b]{2}{*}{ Creative profession } & \multirow[b]{2}{*}{ NYK code $^{a}$} & \multirow[b]{2}{*}{ Males, $n(\%)$} & \multirow[b]{2}{*}{ Females, $n(\%)$} & \multirow{2}{*}{$\begin{array}{l}\text { Age, years: } \\
\text { mean (median) }\end{array}$} & \multirow{2}{*}{$\begin{array}{c}\text { Annual income, } \\
\text { krona: mean (median) }\end{array}$} & \multicolumn{2}{|c|}{ Living area, $n(\%)$} \\
\hline & & & & & & Rural & Urban \\
\hline $\begin{array}{r}\text { Scientific occupations } \\
\text { University teachers }\end{array}$ & 051 & $20988(70.3)$ & $8878(29.7)$ & $47.0(46.2)$ & $218(215)$ & $2190(7.3)$ & $27676(92.7)$ \\
\hline $\begin{array}{l}\text { Visual artistic occupations } \\
\text { Visual artists } \\
\text { Photographers } \\
\text { Designers } \\
\text { Display artists }\end{array}$ & $\begin{array}{l}081 \\
946 \\
082 \\
083\end{array}$ & $23896(59.2)$ & $16463(40.8)$ & $47.4(46.0)$ & $118(115)$ & $5053(12.5)$ & $35306(87.5)$ \\
\hline $\begin{array}{l}\text { Non-visual artistic occupations } \\
\text { Performing artists } \\
\text { Composers and musicians } \\
\text { Authors } \\
\text { Other literary and artistic work }\end{array}$ & $\begin{array}{l}086 \\
087 \\
084 \\
088\end{array}$ & $16342(63.7)$ & $9298(36.3)$ & $45.5(43.6)$ & $134(131)$ & $2780(10.8)$ & $22860(89.2)$ \\
\hline Accountants and auditors & 091 & $12670(63.9)$ & 7149 (36.1) & $44.6(42.8)$ & 199 (185) & $1482(7.5)$ & $18337(92.5)$ \\
\hline
\end{tabular}


accountants as one of the occupations with predominantly conventional qualities. ${ }^{29}$ Descriptive data for the different occupational groups in the census from 1990 are presented in Table 1. Scientific occupations were defined as Nordic Classification of Occupations code 051: University teachers. This group is described by Statistics Sweden as individuals 'conducting research and teaching at the university', including occupations that generally require active research or examination at the $\mathrm{PhD}$ level, ${ }^{31}$ excluding researchers only active outside of the academic field.

Information on occupations is based on mandatory self-report questionnaires that were mailed to every household in Sweden. The censuses are more than $99 \%$ complete. ${ }^{32}$ The validity of the occupational information in the Swedish censuses has also been investigated by comparing survey data collected during personal interviews in 1977 and 1979-1981 to census data from 1980, with a high level of agreement between the two sources (i.e. Nordic Classification of Occupations 3-digit level: approximately 70\%; 2-digit level: approximately $80 \%$; 1-digit level: approximately $90 \%)^{33}$

We compared non-response rates regarding occupation among those with a psychiatric diagnosis (the case group) and the control group and their siblings without a psychiatric diagnosis. Those in the case group had higher rates of missing data than their respective controls (schizophrenia: 55\% v. 20\%; bipolar disorder: $25 \%$ v. $18 \%$; unipolar depression: $25 \%$ v. $22 \%$ ), whereas healthy siblings of those in the case group had similar rates of missing data compared with their respective controls (schizophrenia: $18 \%$ v. $15 \%$; bipolar disorder: $16 \%$ v. $14 \%$; unipolar depression: $18 \%$ v. 17\%). To understand how missing data status influenced the associations, we compared the prevalence of creativity in siblings of those in the case group with or without missing data on occupation. Siblings of people with schizophrenia with a missing value significantly more often had creative professions compared with siblings of those with schizophrenia with a valid occupation $(2.57 \%$ v. $1.95 \%$, $P<0.001)$. The opposite was true for siblings of people with unipolar depression $(1.14 \%$ v. $1.57 \%, P<0.001)$. No significant differences were found in siblings of those with bipolar disorder.

\section{IQ}

In Sweden, conscription and associated assessment of IQ is compulsory for males, but individuals with known severe medical and psychological handicaps living in institutions were excluded (approximately 2\% in the beginning of the 1990s; B. Carlstedt, personal communication, 2011). Two tests were used during the study period. The first test (1969-1994) was based on written questionnaires, and the second (1994 and onwards) was computer based. Both tests address four dimensions of the intelligence construct (logical/inductive, verbal, spatial/visual and theoretical/ technical) and include 160 questions (40 for each dimension). ${ }^{34}$ Results were presented from 1 to 9 , standardised against the entire population with a mean of $5($ s.d. $=2)$. A higher value indicates greater cognitive capacity.

\section{Statistical analysis}

We used a nested case-control strategy to study associations between having a creative occupation and being diagnosed with schizophrenia, bipolar disorder or unipolar depression or being a first-, second-, or third-degree relative of these individuals. Ten individuals matched on gender and birth year were randomly selected as controls from the Multi-Generation Register for each person in the case group and each of their relatives; controls had to be alive, within the country, and without any in-patient episode for the studied disorder at the date of the first hospitalisation of the individual in the case group (incidence density sampling). This method avoids bias due to the complication that individuals in the population registers enter the study at different times (i.e. left truncation) and allows equal follow-up time of relatives of those in the case and the control groups. ${ }^{35}$ To assess the association between a creative occupation across each class of the case group and relatives, we estimated odds ratios using conditional logistic regression in PROC PHREG in SAS version 9.2 on Windows XP professional. The odds ratios presented can be viewed as risk ratios, considering the use of incidence density sampling. Since several correlated pairs of relatives from every family could be included in an analysis, a robust sandwich estimator was used to adjust for the correlated data when calculating the confidence intervals.

To further investigate the familial effect, we examined the rates of creative occupations in non-affected half-siblings of those in the case group who shared either a mother (maternal half-siblings) or a father (paternal half-siblings). The rationale for this comparison is that maternal half-siblings are exposed more to common environments than are paternal half-siblings, but are equally genetically related (on average 25\%); that is, not only have maternal half-siblings been exposed to a similar intrauterine environment, it has also been observed that $91 \%$ of children stay with their mother after a divorce. ${ }^{36}$ Thus, if creative occupations were more common in maternal half-siblings compared with paternal half-siblings, this would suggest that early environmental factors are important in determining creativity. ${ }^{35}$

\section{Results}

We identified 54042 people (29479 males and 24563 females) with schizophrenia, 29644 people (11910 males and 17734 females) with bipolar disorder and 217771 people (84352 males and 133419 females) with unipolar depression. Since the data in the registries are longitudinal and truncated, descriptive data for the case group (Table 2) are presented only for individuals born in 1958. The numbers in the case group, control group and relatives in the different creative occupations are presented in online Table DS1.

\section{Creative occupations}

The main associations between schizophrenia, bipolar disorder, unipolar depression and creative occupations are illustrated in

Table 2 Descriptive data for the case group born in 1958

\begin{tabular}{|c|c|c|c|c|c|c|c|}
\hline \multirow[b]{2}{*}{ Diagnosis } & \multirow[b]{2}{*}{ Males, $n(\%)$} & \multirow[b]{2}{*}{ Females, $n(\%)$} & \multirow{2}{*}{$\begin{array}{l}\text { Age at first discharge, } \\
\text { years: mean (median) }\end{array}$} & \multirow{2}{*}{$\begin{array}{l}\text { Number of discharges, } \\
\text { mean (median) }\end{array}$} & \multicolumn{3}{|c|}{ Living area, ${ }^{a} n(\%)$} \\
\hline & & & & & Rural & Urban & Missing \\
\hline Schizophrenia & $513(64.0)$ & $289(36.0)$ & $30.4(29.9)$ & $7.5(4)$ & $53(6.6)$ & 669 (83.4) & $80(10.0)$ \\
\hline Bipolar disorder & $146(38.4)$ & $234(61.6)$ & $33.6(33.8)$ & $4.5(2)$ & $48(12.6)$ & $315(82.9)$ & $17(4.5)$ \\
\hline Unipolar depression & 782 (41.3) & $1113(58.7)$ & $33.0(35.2)$ & $2.0(1)$ & $255(13.5)$ & $1517(80.1)$ & $123(6.5)$ \\
\hline
\end{tabular}




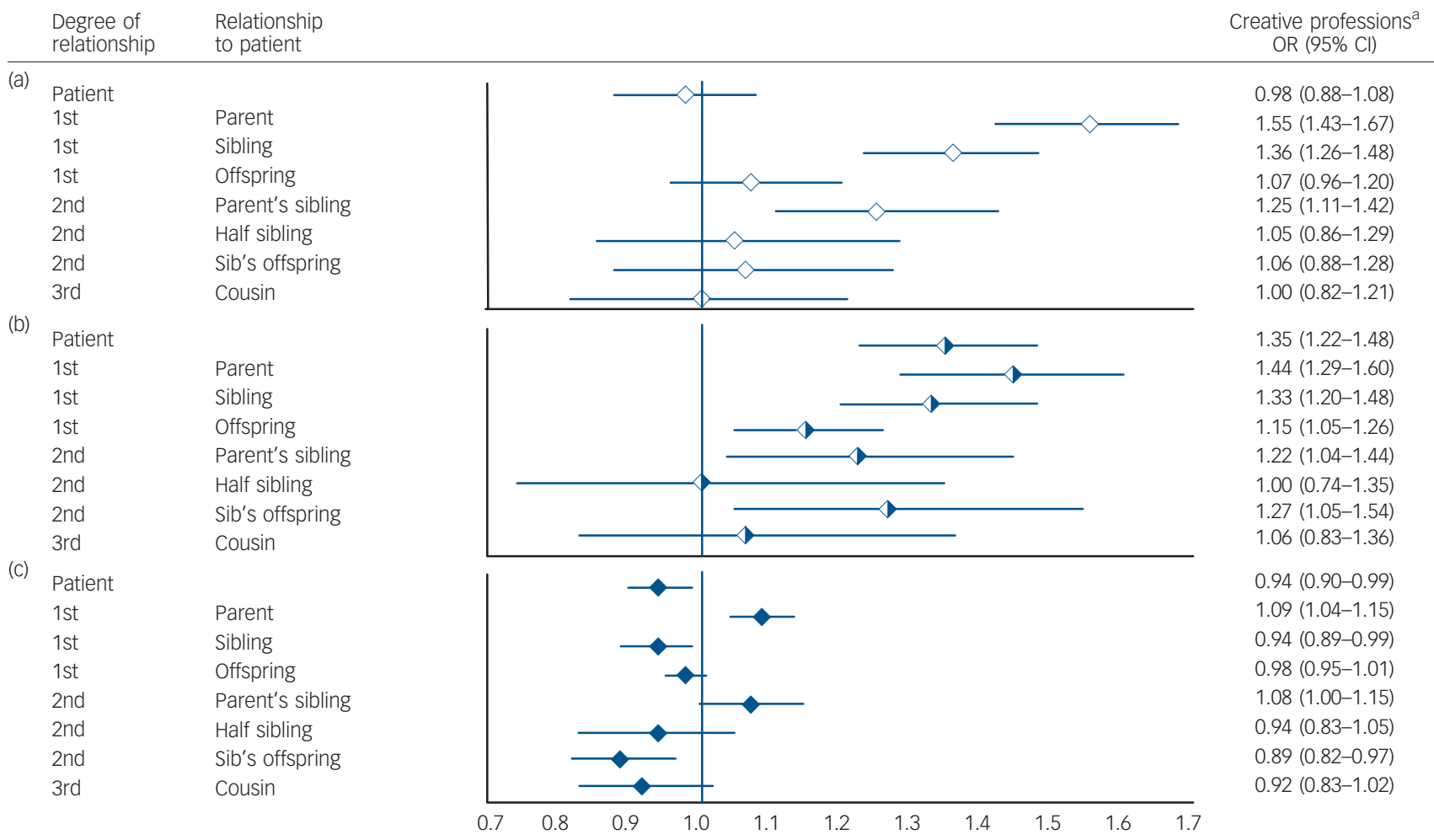

Fig. 1 Associations between case group psychiatric morbidity and creative professions.

(a) schizophrenia; (b) bipolar disorder; (c) unipolar depression. Relatives of all those in the case group were not allowed to have any event of schizophrenia, bipolar disorder or unipolar depression.

$\mathrm{OR}$, odds ratio.

a. Including scientific and artistic occupations.

Fig. 1 and online Table DS2. Since no major differences were found between females and males, only pooled results are presented.

\section{Schizophrenia subgroup}

Compared with the control group, those with schizophrenia (odds ratio $(\mathrm{OR})=0.98,95 \% \mathrm{CI} 0.88-1.08)$ demonstrated no difference in having a creative profession (Fig. 1), but showed a significantly decreased likelihood of holding a scientific occupation $(\mathrm{OR}=0.63$, 95\% CI 0.51-0.79; online Table DS2). There was also a significant increase in the likelihood of holding an artistic occupation $(\mathrm{OR}=1.14,95 \% \mathrm{CI} 1.01-1.28)$, which in turn was mainly as a result of an increase in visual artistic occupations $(\mathrm{OR}=1.30$, 95\% CI 1.13-1.49).

Parents and siblings of people with schizophrenia were significantly more likely to hold a creative profession compared with the control group $\left(\mathrm{OR}_{\text {Parents }}=1.55,95 \%\right.$ CI $1.43-1.67$; $\mathrm{OR}_{\text {Siblings }}=1.36,95 \%$ CI 1.26-1.48). This increase was present across all creative domains. Offspring of those in the schizophrenia subgroup showed no significant increase in creative professions overall, although there was an increased likelihood of holding an artistic occupation, primarily of the visual domain $(\mathrm{OR}=1.38,95 \%$ CI 1.18-1.62), a finding that is in line with the individuals with schizophrenia. In general, no significant associations were found in second- and third-degree relatives of those in the schizophrenia subgroup compared with the control group.

\section{Bipolar disorder subgroup}

Individuals with bipolar disorder were significantly overrepresented in creative professions compared with the control group $(\mathrm{OR}=1.35,95 \%$ CI $1.22-1.48)$. This was primarily because of an increased likelihood of both visual $(\mathrm{OR}=1.42$, 95\% CI 1.23-1.64) and non-visual (OR=1.44, 95\% CI 1.20-1.73) artistic occupations.

First-degree relatives of those with bipolar disorder were more likely than those in the control group to hold a creative profession in general (Fig. 1), with higher odds ratios for scientific than artistic occupations (online Table DS2). As with the schizophrenia subgroup, second- and third-degree relatives of those in the bipolar subgroup in general showed no significantly increased rate of creative occupations, except that uncles/aunts and nephew/ nieces were more likely to have a scientific occupation.

\section{Unipolar depression subgroup}

Individuals with unipolar depression showed no increased rate of overall creative professions $(\mathrm{OR}=0.94,95 \%$ CI $0.90-0.99)$. Similarly, there was no consistent pattern with respect to the frequency of creative occupations in relatives of those with unipolar depression.

\section{Accountants and auditors}

People with bipolar disorder and their first-degree relatives generally displayed no significant associations with accountants and auditors, whereas those with schizophrenia or unipolar depression and their first-degree relatives generally displayed significant decreases in the likelihood of holding such an occupation. More distant relatives of individuals of all three diagnoses generally showed no significant associations with accountants and auditors. 
Table 3 Mean IQ Stanine scores stratified by type of profession or psychiatric morbidity ${ }^{\text {a }}$

\begin{tabular}{|c|c|c|c|c|}
\hline & \multicolumn{4}{|c|}{ Mean $(95 \% \mathrm{Cl})$} \\
\hline & Patient & First-degree relative & Second-degree relative & Third-degree relative \\
\hline \multicolumn{5}{|l|}{ Profession } \\
\hline Creative professions $^{b}$ & $6.40(6.37-6.43)$ & $6.05(6.04-6.06)$ & $5.74(5.72-5.75)$ & $5.46(5.44-5.49)$ \\
\hline Scientific occupations & $7.52(7.48-7.56)$ & $6.70(6.68-6.72)$ & $6.21(6.18-6.23)$ & $5.78(5.71-5.84)$ \\
\hline Artistic occupations & $5.88(5.85-5.91)$ & $5.72(5.70-5.73)$ & $5.51(5.49-5.53)$ & $5.40(5.37-5.43)$ \\
\hline Accountants and auditors & $6.38(6.33-6.43)$ & $6.03(6.00-6.05)$ & $5.64(5.61-5.67)$ & $5.40(5.35-5.44)$ \\
\hline \multicolumn{5}{|l|}{ Psychiatric morbidity } \\
\hline Schizophreniac $^{c}$ & $4.06(4.02-4.11)$ & $4.74(4.71-4.77)$ & $4.88(4.85-4.90)$ & $4.92(4.89-4.96)$ \\
\hline Bipolar disorder ${ }^{c}$ & $4.80(4.72-4.87)$ & $5.09(5.06-5.12)$ & $5.10(5.07-5.13)$ & $5.05(5.00-5.09)$ \\
\hline Unipolar depression $^{c}$ & $4.43(4.39-4.46)$ & $4.80(4.79-4.81)$ & $4.78(4.77-4.79)$ & $4.88(4.86-4.89)$ \\
\hline No diagnosis ${ }^{d}$ & $5.10(5.10-5.10)$ & $5.09(5.08-5.09)$ & $4.94(4.94-4.95)$ & $5.03(5.03-5.03)$ \\
\hline \multicolumn{5}{|c|}{$\begin{array}{l}\text { a. Men only. } \\
\text { b. Including scientific and artistic occupations. } \\
\text { c. Relatives were not allowed to have any diagnosis of schizophrenia, bipolar disorder or unipolar depression. } \\
\text { d. No diagnosis of schizophrenia, bipolar disorder or unipolar depression in the Hospital Discharge Register. }\end{array}$} \\
\hline
\end{tabular}

\section{Half-siblings and IQ}

We found no consistent pattern of differences between maternal and paternal half-siblings (creative professions maternal $v$. paternal: schizophrenia $\mathrm{OR}=1.26(95 \%$ CI $0.91-1.74)$ v. $1.08 \quad(95 \%$ CI 0.82-1.41); bipolar disorder: $\mathrm{OR}=1.21(95 \%$ CI $0.75-1.94)$ v. 1.03 (95\% CI 0.71-1.49); unipolar depression: 0.81 (95\% CI $0.66-$ 1.00) v. 0.98 (95\% CI 0.85-1.14); online Table DS2).

We found that IQ (men only) was generally higher in people with creative occupations, but lower in those with schizophrenia, bipolar disorder, unipolar depression and their respective relatives,

Table 4 Associations between case group psychiatric morbidity and creative occupations adjusted for $\mathrm{IQ}^{\mathrm{a}}$

\begin{tabular}{|c|c|c|}
\hline & \multicolumn{2}{|c|}{ Odds ratio $(95 \% \mathrm{Cl})$} \\
\hline & Crude $^{\text {b }}$ & IQ adjusted \\
\hline \multicolumn{3}{|c|}{ Creative professions $^{C}$} \\
\hline \multicolumn{3}{|c|}{ Schizophrenia } \\
\hline Patient & $0.79(0.60-1.06)$ & $1.11(0.82-1.49)$ \\
\hline Sibling & $1.41(1.19-1.67)$ & $1.50(1.27-1.78)$ \\
\hline \multicolumn{3}{|c|}{ Bipolar disorder } \\
\hline Patient & $1.35(0.98-1.87)$ & $1.51(1.09-2.08)$ \\
\hline Sibling & $1.51(1.20-1.89)$ & $1.50(1.19-1.88)$ \\
\hline \multicolumn{3}{|c|}{ Unipolar depression } \\
\hline Patient & $0.82(0.69-0.97)$ & $1.03(0.87-1.22)$ \\
\hline Sibling & $0.92(0.82-1.04)$ & $1.04(0.92-1.16)$ \\
\hline \multicolumn{3}{|c|}{ Scientific occupations } \\
\hline \multicolumn{3}{|c|}{ Schizophrenia } \\
\hline Patient & $0.55(0.31-0.99)$ & $1.09(0.60-1.99)$ \\
\hline Sibling & $1.72(1.31-2.25)$ & $1.93(1.47-2.54)$ \\
\hline \multicolumn{3}{|c|}{ Bipolar disorder } \\
\hline Patient & $1.20(0.64-2.27)$ & $1.44(0.76-2.72)$ \\
\hline Sibling & $1.63(1.13-2.37)$ & $1.61(1.11-2.34)$ \\
\hline \multicolumn{3}{|c|}{ Unipolar depression } \\
\hline Patient & $0.56(0.40-0.80)$ & $0.86(0.60-1.22)$ \\
\hline Sibling & $0.91(0.74-1.11)$ & $1.12(0.91-1.37)$ \\
\hline \multicolumn{3}{|c|}{ Artistic occupations } \\
\hline \multicolumn{3}{|c|}{ Schizophrenia } \\
\hline Patient & $0.92(0.66-1.27)$ & $1.11(0.79-1.55)$ \\
\hline Sibling & $1.27(1.03-1.56)$ & $1.32(1.07-1.62)$ \\
\hline \multicolumn{3}{|c|}{ Bipolar disorder } \\
\hline Patient & $1.40(0.97-2.03)$ & $1.51(1.04-2.19)$ \\
\hline Sibling & $1.50(1.13-1.99)$ & $1.49(1.13-1.98)$ \\
\hline \multicolumn{3}{|c|}{ Unipolar depression } \\
\hline Patient & $0.94(0.78-1.14)$ & $1.09(0.90-1.32)$ \\
\hline Sibling & $0.93(0.81-1.07)$ & $1.00(0.87-1.15)$ \\
\hline \multicolumn{3}{|c|}{$\begin{array}{l}\text { a. Siblings of all those in the case group were not allowed to have any event of } \\
\text { schizophrenia, bipolar disorder or unipolar depression. IQ only available for males. } \\
\text { b. In the study subpopulation with IQ data available. } \\
\text { c. Including scientific and artistic occupations. }\end{array}$} \\
\hline
\end{tabular}

compared with people without any of the three diagnoses (Table 3). To determine whether IQ mediated the association between creativity and psychopathology, it was included as a continuous covariate in the regression model. As a result, however, the associations were strengthened rather than attenuated (Table 4). No significant interaction effects between IQ and creative occupations were found.

\section{Discussion}

\section{Main findings}

This Swedish total population case-control study is several magnitudes larger than previous studies and demonstrates an increased likelihood for both people with schizophrenia and bipolar disorder, as well as for their respective relatives, to work in a creative occupation, compared with controls. Differences in IQ (available for men only) did not account for these associations. Thus, the present study lends strong support to the notion that creativity is familiarly coupled to schizophrenia and bipolar disorder, which has been suggested in prior studies. ${ }^{2,10-20,37}$

By contrast, individuals with unipolar depression and their relatives demonstrated no consistent pattern of associations with artistic and scientific occupations. This indicates that creative occupations are specifically linked to schizophrenia and bipolar disorder rather than to psychopathology per se. Furthermore, the lack of positive associations with accountants and auditors in any of the studied diagnoses compared with the control group suggests that the artistic and scientific occupations are specific for creativity.

Even though the present study does not explain what mechanisms may underlie the observed association between mental disorder and creative occupations, it is noteworthy that the likelihood of creative occupations in relatives of those in the case group was highest among healthy first-degree relatives and this gradually decreased with increasing familial distance to these individuals. Additionally, there were no significant differences between the maternal and paternal half-siblings. These results hence suggest a genetic rather than environmental explanation to the familial cosegregation of creativity and psychopathology, even though the comparison between maternal and paternal half-siblings had low power. Related to this, a recent intriguing finding is the associations between creativity and specific genetic polymorphisms. $^{38}$

\section{Balancing selection hypothesis}

One hypothesis as to why psychiatric disorders have remained throughout evolution is the balancing selection hypothesis, which 
assumes that susceptibility alleles to mental disorders in patients or relatives also harbour adaptive advantages that increase fitness. ${ }^{7,39,40}$ Along with creativity, other balancing benefits have been suggested; for example, bipolar disorder as an adaption to long winters and schizophrenia as a consequence of language evolution. ${ }^{41,42}$ The balancing selection hypothesis fits with the present study in which the association with creativity peaks in first-degree relatives of those with a mental disorder, rather than in the patients themselves. This is congruent with the so called 'inverted-U' relationship between creativity and psychopathology. ${ }^{18}$ Hence, in absence of a debilitating illness, the relatives of those with schizophrenia or bipolar disorder might benefit from increased creativity, which in turn might increase fitness. Creativity has for example been coupled to an increased number of sexual partners. ${ }^{8}$ This could thus be one explanation why these disorders have prevailed throughout human history. ${ }^{7-9,43}$ However, theoretical work and available empirical data are contradictory; ${ }^{7}$ among others, findings of reduced fertility in people with schizophrenia and their relatives disagree with this notion. ${ }^{5-6,44}$ This has led some authors to propose the alternative mutation selection hypothesis, which instead suggests that psychiatric disorders simply reflect mutational load. ${ }^{7}$

\section{Creative occupations in schizophrenia $v$. bipolar disorder}

Two general patterns emerged when people with schizophrenia and their relatives were compared with those with bipolar disorder and their relatives. First, those with schizophrenia were less likely than those with bipolar disorder to hold a creative profession. Second, relatives of people with schizophrenia and bipolar disorder were overrepresented in both artistic and scientific occupations; however, whereas relatives of those with schizophrenia had their highest increased rate in artistic occupations, relatives of individuals with bipolar disorder were instead more overrepresented in scientific occupations. Interestingly, the latter finding corroborates Juda's finding that schizophrenia occurs in artists and bipolar disorder in scientists. ${ }^{11}$ The schizophrenic spectrum has been proposed to convey a decrease in common sense, demonstrated by individuals with schizophrenia outperforming controls in logical deduction that is in conflict with common sense. ${ }^{45,46}$ To be less restrained by common sense might, speculatively, confer an advantage in artistic occupations but a disadvantage in scientific occupations. ${ }^{28}$ The increased creativity in bipolar disorder, on the other hand, might be driven by hypomanic periods with ensuing augmented fluency, ${ }^{47,48}$ which is an important aspect of creativity. ${ }^{21}$ This assumption is supported by increased productivity in creative individuals during hypomania. ${ }^{13}$

\section{Strengths and limitations}

Along with nationwide representation and absence of selection bias, the major strength of this study is that we were able to study the relatives of affected individuals. This circumvents the bias sequels that the mental disorders per se exert on any measure of creativity. The main finding of this study is therefore that the non-affected first-degree relatives of people with schizophrenia or bipolar disorder demonstrated increased creativity compared with a control group, whereas the individuals in the case group themselves showed only modest increases in creativity.

One limitation with this study is the narrow definition of scientific occupations as those solely active within the academic area. A second limitation is the use of different diagnostic systems (i.e. ICD-8, ICD-9 and ICD-10) throughout the cohort. Finally, the general use of artistic and scientific occupations as a proxy for creativity is a limitation, considering the many different ways to measure creativity. ${ }^{49}$ But, although creativity could be assumed to be an essential part in many different occupations and areas of life, it has been argued that creativity is at the core of artistic and scientific occupations. ${ }^{50}$ Feist has also demonstrated that artists and scientists have shared psychological traits. ${ }^{28}$ Nevertheless, the consequential restriction of this study to creativity expressed in working life should be noted given that schizophrenia might be more associated with creative avocations rather than vocational activities. ${ }^{20}$ Individuals with schizophrenia in this study also had a limited response rate on occupational status (45\%), potentially introducing bias due to missing data. However, since creative professions were more common among the siblings of those with schizophrenia with missing values regarding occupation, the lack of association in people with schizophrenia could possibly be an underestimation of the true association.

In conclusion, the present study found a clear association between specific psychopathologies and creative occupations. Although it is tempting to speculate that this might explain the paradox that mental disorders persist through evolution despite decreased fitness, there are many other plausible theories addressing this issue. ${ }^{40-42}$ Future studies are needed to elucidate if creativity is distinct from other human traits, such as intelligence or language, that might confer increased risk for psychosis. ${ }^{39}$

\section{Simon Kyaga, MD, Paul Lichtenstein, PhD, Marcus Boman, BSC, Department of Medical Epidemiology and Biostatistics, Karolinska Institutet, Stockholm; Christin Hultman, PhD, Department of Medical Epidemiology and Biostatistics, Karolinska Hultman, PhD, Department of Medical Epidemiology and Biostatistics, Karolin
Institutet, Stockholm, and Department of Neuroscience, Psychiatry, Ulleråker, Uppsala; Niklas Långström, MD, PhD, Department of Medical Epidemiology and Biostatistics, Karolinska Institutet, Stockholm, and Center for Violence Prevention, Karolinska Institutet, Stockholm; Mikael Landén, MD, PhD, Department of Medical Epidemiology and Biostatistics, Karolinska Institutet, Stockholm, and Institute of Neuroscience and Physiology, University of Gothenburg, Gothenburg, and Department of Clinical Neuroscience, Karolinska Institutet, Stockholm, Sweden}

Correspondence: Simon Kyaga, Department of Epidemiology and Biostatistics, Karolinska Institutet, POB 281, SE 17177 Stockholm, Sweden. Email: simon.kyaga@ki.se

First received 7 Aug 2010, final revision 24 Nov 2010, accepted 23 Feb 2011

\section{Funding}

Financial support was provided through grants from the Swedish Medical Research Council (K2008-62x-14647-06-3), The Swedish Psychiatry Foundation (Psykiatrifonden), The Bror Gadelius Foundation and the Swedish Council for Working Life and Social Research.

\section{References}

1 Motto AL, Clark JR. The paradox of genius and madness: Seneca and his influence. Cuadernos de Filología Clásica. Estudios Latinos 1992; 2: 189-200.

2 Post F. Creativity and psychopathology. A study of 291 world-famous men. Br J Psychiatry 1994; 165: 22-34.

3 Nelson B. Its own reward: a phenomological study of artistic creativity. J Phenomological Psychol 2007; 38: 217-55.

4 Schou M. Artistic productivity and lithium prophylaxis in manic-depressive illness. Br J Psychiatry 1979; 135: 97-103.

5 Lewis A. Fertiliy and mental illness. Eugen Rev 1958; 50: 91-106.

6 Essenmoller E. Mating and fertility patterns in families with schizophrenia. Eugen Quart 1959; 6: 142-7.

7 Keller MC, Miller G. Resolving the paradox of common, harmful, heritable mental disorders: which evolutionary genetic models work best? Behav Brain Sci 2006; 29: 385-404; discussion 405-52.

8 Nettle D, Clegg H. Schizotypy, creativity and mating success in humans. Proc Biol Sci 2006; 273: 611-5.

9 Pearlson GD, Folley BS. Schizophrenia, psychiatric genetics, and Darwinian psychiatry: an evolutionary framework. Schizophr Bull 2008; 34: 722-33. 
10 Lange-Eichbaum W, Paul ME. The Problem of Genius (trans. Eden \& Cedar Paul): xix, 187. Kegan Paul \& Co, 1931.

11 Juda $A$. The relationship between highest mental capacity and psychic abnormalities. Am J Psychiatry 1949; 106: 296-307.

12 Andreasen NC. Creativity and mental illness: prevalence rates in writers and their first-degree relatives. Am J Psychiatry 1987; 144: 1288-92.

13 Jamison KR. Mood disorders and patterns of creativity in British writers and artists. Psychiatry - Interpersonal Biol Processes 1989; 52: 125-34.

14 Ludwig AM. Creative achievement and psychopathology - comparison among professions. Am J Psychother 1992; 46: 330-56.

15 Santosa CM, Strong CM, Nowakowska C, Wang PW, Rennicke CM, Ketter TA Enhanced creativity in bipolar disorder patients: a controlled study. J Affect Disord 2007; 100: 31-9.

16 Simeonova DI, Chang KD, Strong C, Ketter TA. Creativity in familial bipolar disorder. J Psychiatr Res 2005; 39: 623-31.

17 Karlsson JL. Genetic association of giftedness and creativity with schizophrenia. Hereditas 1970; 66: 177-82.

18 Richards R, Kinney DK, Lunde I, Benet M, Merzel AP. Creativity in manicdepressives, cyclothymes, their normal relatives, and control subjects. J Abnorm Psychol 1988; 97: 281-8.

19 McNeil TF. Prebirth and postbirth influence on the relationship between creative ability and recorded mental illness. J Pers 1971; 39: 391-406.

20 Kinney DK, Richards R, Lowing PA, LeBlanc D, Zimbalist ME, Harlan P. Creativity in offspring of schizophrenic and control parents: an adoption study. Creat Res J 2000; 13: 17-25.

21 Goodwin FK, Jamison KR. Manic-Depressive Illness. Oxford University Press, 2007.

22 World Health Organization. International Statistical Classification of Diseases and Related Health Problems (ICD-8). WHO, 1967.

23 World Health Organization. International Statistical Classification of Diseases and Related Health Problems (ICD-9). WHO, 1978.

24 World Health Organization. The ICD-10 Classification of Mental and Behavioural Disorders: Clinical Descriptions and Diagnostic Guidelines. WHO, 1992.

25 Ekholm B, Ekholm A, Adolfsson R, Vares M, Osby U, Sedvall GC, et al. Evaluation of diagnostic procedures in Swedish patients with schizophrenia and related psychoses. Nord J Psychiatry 2005; 59: 457-64.

26 Bock C, Bukh JD, Vinberg M, Gether U, Kessing LV. Validity of the diagnosis of a single depressive episode in a case register. Clin Pract Epidemol Ment Health 2009; 5: 4

27 Arbetsmarknadsstyrelsen. Klassificering Nordisk Yrkes Klassificering Svensk grundstandard [Nordic Classification of Occupations] Arbetsmarknadsstyrelsen, 1983.

28 Feist GJ. A meta-analysis of personality in scientific and artistic creativity. Pers Soc Psychol Rev 1998; 2: 290-309.

29 Holland JL. Making Vocational Choices: A Theory of Vocational Personalities and Work Environments (3rd edn). Psychological Assessment Resources, 1997.

30 Baer J. The case for domain specificity of creativity. Creat Res J 1998; 11: 173-7.

31 Statistiska Centralbyrån. Systematisk Förteckning över Yrken YK 80, Yrkesklassificering Tillämpad i FOB 80 samt FOB 85 och FOB 90 [Systematic
Directory of Occupations YK 80, Job Classifications applied in the Census 80 and Census 85 and Census 1990]. Statistiska Centralbyrån, 1990.

32 Norman A, Moradi T, Gridley G, Dosemeci M, Rydh B, Nyrén O, et al. Occupational physical activity and risk for prostate cancer in a nationwide cohort study in Sweden. Br J Cancer 2002; 86: 70-5.

33 Wärneryd $B$, Thorslund $M$, Östlin $\mathrm{P}$. The quality of retrospective questions about occupational history - a comparison between survey and census-data. Scand J SOC Med 1991; 19: 7-13.

34 Mårdberg B, Carlstedt B. Swedish Enlistment Battery (SEB): construct validity and latent variable estimation of cognitive abilities by the CAT-SEB. Int J Sel Assess 1998; 6: 107-14.

35 Lichtenstein P, Yip BH, Björk C, Pawitan Y, Cannon TD, Sullivan, PF, et al. Common genetic determinants of schizophrenia and bipolar disorder in Swedish families: a population-based study. Lancet 2009; 373: 234-9.

36 Statistiska Centralbyrån. Fakta om den Svenska Familjen - sammansättning och förändringar från bardom till ålderdom. Demografiska Rapporter. [Facts about the Swedish family - composition and changes from childhood to old age. Demographic reports.] Statistiska Centralbyrån, 1994.

37 Tremblay $\mathrm{CH}$, Grosskopf S, Yang K. Brainstorm: occupational choice, bipolar illness and creativity. Econ Hum Biol 2010; 8: 233-41.

38 Keri S. Genes for psychosis and creativity: a promoter polymorphism of the neuregulin 1 gene is related to creativity in people with high intellectual achievement. Psychol Sci 2009; 20: 1070-3.

39 Nichols C. Is there an evolutionary advantage of schizophrenia? Pers Ind Diff 2009; 46: 832-8.

40 Horrobin DF. Schizophrenia: the illness that made us human. Med Hypotheses 1998; 50: 269-88.

41 Sherman JA. Evolutionary origin of bipolar disorder (EOBD). Psycoloquy 2001; 12: 1.

42 Crow TJ. The 'big bang' theory of the origin of psychosis and the faculty of language. Schizophr Res 2008; 102: 31-52.

43 Miller GF. The Mating Mind: How Sexual Choice Shaped the Evolution of Human Nature (1st edn). Doubleday, 2000.

44 Svensson AC, Lichtenstein P, Sandin S, Hultman CM. Fertility of first-degree relatives of patients with schizophrenia: a three generation perspective. Schizophr Res 2007; 91: 238-45.

45 Raballo A, Saebye D, Parnas J. Looking at the schizophrenia spectrum through the prism of self-disorders: an empirical study. Schizophr Bull 2011; 37: $344-51$

46 Owen GS, Cutting J, David AS. Are people with schizophrenia more logical than healthy volunteers? Br J Psychiatry 2007; 191: 453-4.

47 MacCabe JH, Lambe MP, Cnattingius S, Shaw PC, David AS, Reichberg A, et al. Excellent school performance at age 16 and risk of adult bipolar disorder: national cohort study. Br J Psychiatry 2010; 196: 109-15.

48 Runco MA. Creativity: Theories and Themes: Research, Development, and Practice. Elsevier Academic Press, 2007.

49 Kaufman JC, Plucker JA, Baer J. Essentials of Creativity Assessment. Wiley, 2008.

50 Florida RL. The Rise of the Creative Class . . . and How it's Transforming Work, Leisure, Community and Everyday Life. Basic Books, 2002. 